\title{
Teores de cálcio em dietas para codornas japonesas no terço final de postura (45 a 57 semanas de idade)
}

\author{
[Levels of calcium in diets for Japanese quails in the third end of posture (45 - 57 weeks of age)] \\ C.H.R. Costa ${ }^{1,5}$, S.L.T. Barreto ${ }^{2}$, P.C. Gomes ${ }^{2}$, G.V.C. Maia ${ }^{3}$, C.A. Lipari $^{4}$, L.H. Hosoda ${ }^{4}$ \\ ${ }^{1}$ Aluno de pós graduação - DZ-UFV - Viçosa, MG \\ ${ }^{2}$ Departamento de Zootecnia - UFV - Viçosa, MG \\ ${ }^{3}$ Departamento de Zootecnia - UFLA - Lavras, MG \\ ${ }^{4}$ Aluno de graduação - UFV - Viçosa, MG \\ ${ }^{5}$ Bolsista do $\mathrm{CNPq}$
}

\begin{abstract}
RESUMO
Verificou-se o efeito dos teores de cálcio (Ca) na dieta sobre o desempenho e a qualidade dos ovos de codornas japonesas durante o terço final do ciclo de produção. Foram utilizadas 350 codornas, com 313 dias de idade, distribuídas em 35 unidades experimentais de 10 aves. O delineamento foi inteiramente ao acaso, composto de cinco níveis de $\mathrm{Ca}-2,2 ; 2,6 ; 3,0 ; 3,4 ; 3,8 \%$-, com sete repetições. O aumento do Ca na dieta melhorou linearmente a conversão por massa e por dúzia de ovos, melhorou a espessura de casca e influenciou o peso da gema e da casca dos ovos, além da porcentagem da casca. Observou-se redução nos teores de $\mathrm{P}$, Ca e Mg na casca com o aumento dos níveis de Ca da dieta. Para os demais parâmetros, não houve efeito do teor de $\mathrm{Ca}$ da dieta. Considerando-se a importância da conversão alimentar, em termos econômicos e de desempenho, o teor de 3,8\% de Ca na dieta mostrou-se satisfatório em atender às demais variáveis relacionadas com a qualidade dos ovos. Dieta que contenha 3,8\% de Ca, correspondendo ao consumo diário de $982 \mathrm{mg}$ por ave, melhora a conversão alimentar e a qualidade da casca dos ovos de codornas japonesas no terço final do ciclo de produção (45 a 57 semanas de idade).
\end{abstract}

Palavras-chave: codorna, conversão alimentar, desempenho, exigência nutricional, espessura de casca, qualidade dos ovos

\begin{abstract}
The effect of calcium ( $\mathrm{Ca}$ ) levels in the diet on performance and egg quality of Japanese quail during the final third of the production cycle was evaluated. A total of 350 313-day-old quails was used. They were distributed in 35 experimental units of 10 birds. The design was completely randomized, composed of five levels of $\mathrm{Ca}$ (2.2, 2.6, 3.0, 3.4 and 3.8\%), with seven replications. The increase of Ca in the diet linearly improved the feed conversion per dozen eggs, improved the shell thickness, and influenced the weight of yolk and egg shell as well the percentage of shell. There was reduction in levels of $P, C a$, and $\mathrm{Mg}$ in the shell with increasing levels of $C a$ in the diet. For other parameters, no effect of calcium levels in the diet was recorded. Considering the importance of feed conversion in economic terms and performance, the level of $3.8 \% \mathrm{Ca}$ in diet showed satisfactory to meet the other variables related to egg quality. Diet containing $3.8 \%$ Ca, corresponding to a daily intake of $982 \mathrm{mg}$ per bird, improves feed conversion and egg shell quality of Japanese quails in the final third of the production cycle (45-57 weeks old).
\end{abstract}

Keywords: quail, feed conversion, performance, nutritional requirement, shell thickness, egg quality, egg mass

Recebido em 23 de novembro de 2009

Aceito em 20 de setembro de 2010

E-mail: hrochacosta@yahoo.com.br 


\section{INTRODUÇÃO}

Dos minerais que normalmente são suplementados em dietas de poedeiras, o $\mathrm{Ca}$ requer atenção especial, por participar, juntamente com o P, de funções metabólicas essenciais no organismo, estando diretamente relacionado à qualidade da casca dos ovos e do tecido ósseo e muscular. O $\mathrm{Ca}$ para as aves adultas é usado para a formação da casca, porém seu excesso na dieta interfere na disponibilidade de outros minerais, tais como o P, Mg, Mn e Zn.

O consumo inadequado de $\mathrm{Ca}$ pode ocasionar anormalidades esqueléticas, queda na postura e má qualidade da casca do ovo, com altos índices de quebra. Portanto, a alimentação de aves de postura tem sido alvo de inúmeras pesquisas, no sentido de adequar os níveis nutricionais com o máximo desempenho econômico das aves. A respeito da suplementação ideal de $\mathrm{Ca}$, existem ainda controvérsias entre os pesquisadores. Para a formulação de rações para codornas, são comumente utilizadas tabelas de exigências nutricionais confeccionadas em outros países (Recomendação..., 1987; Nutrient..., 1994). Nas tabelas dessas publicações, observa-se que não há uniformidade na determinação dos períodos referidos para as fases inicial e de crescimento, e nos níveis nutricionais recomendados para as fases inicial e de produção de ovos (Murakami e Ariki, 1998).

As exigências nutricionais de codornas japonesas são citadas no NRC (Nutrient..., 1994), sem a precisão do término do período de crescimento, ao passo que, no AEC (Recomendação..., 1987), há a divisão da fase inicial de criação em períodos de zero a três e quatro a sete semanas. Em ambas as tabelas, as exigências nutricionais na fase de postura são citadas em apenas uma fase para todo o período de produção. Não obstante, as recomendações de $\mathrm{Ca}$ do AEC (Recomendação..., 1987) são substancialmente mais elevadas que as do NRC (Nutrient..., 1994). Neste, a exigência nutricional de $\mathrm{Ca}$ é de 2,5\% para codornas japonesas em postura. No INRA (Instituto..., 1999), as recomendações ficam entre 3,0 a $3,4 \%$ de $\mathrm{Ca}$, dependendo do nível de energia da dieta, para a mesma fase citada anteriormente.

Segundo Shirivastav e Panda (1999), as recomendações de $\mathrm{Ca}$ para codornas de postura de zero a duas semanas de vida são de $0,8 \%$, de três a cinco semanas de vida $0,6 \%$, e as com mais de seis semanas de vida supririam suas necessidades nutricionais com 3,0\% de $\mathrm{Ca}$.

Pelo fato de não haver dados produtivos que mostrem até quando é viável a suplementação de $\mathrm{Ca}$ e a manutenção do lote de codornas japonesas após o pico de postura, direcionou-se um estudo sobre a exigência nutricional de $\mathrm{Ca}$, com o objetivo de avaliar os efeitos desse mineral sobre o desempenho e a qualidade dos ovos produzidos por essa espécie.

\section{MATERIAL E MÉTODOS}

Foram utilizadas 350 codornas japonesas (Coturnix coturnix japonica), em terço final do ciclo de postura, com 313 dias de idade, durante os quatro períodos experimentais de 21 dias. O delineamento experimental foi inteiramente ao acaso, sendo constituído de cinco tratamentos 2,$2 ; 2,6 ; 3,0 ; 3,4$ e $3,8 \%$ de Ca na dieta -, com sete repetições e 10 aves por unidade experimental. Foram formuladas cinco dietas experimentais, isocalóricas, isoproteicas, isoaminoacídicas e isofosfóricas, à base de milho e farelo de soja (Tab. 1).

As dietas foram formuladas para atender às exigências nutricionais das codornas, segundo recomendações preconizadas pelo NRC (Nutrient...., 1994), exceto para as exigências de metionina + cistina digestível, lisina digestível, treonina digestível, triptofano digestível e de fósforo, que foram baseadas, respectivamente, nas recomendações de Pinto et al. (2003 a,b), Costa et al. (2007), Umigi et al. (2007) e Pinheiro et al. (2008).

Temperatura $\left({ }^{\circ} \mathrm{C}\right)$ e umidade relativa $(\%)$ foram monitoradas duas vezes ao dia, às $8 \mathrm{~h}$ e às $16 \mathrm{~h}$, por meio de termômetros de máxima e mínima e de bulbo seco e bulbo úmido posicionados em pontos estratégicos no galpão.

As aves utilizadas no experimento tinham aproximadamente 45 semanas de vida, tendo, portanto, ultrapassado o pico de postura. Elas continuaram recebendo 17 horas de luz diária até o término do período experimental, quando já apresentavam 397 dias de idade (aproximadamente 57 semanas de vida). 
Tabela 1. Composição percentual, química e valores nutricionais das dietas para codornas japonesas no terço final do ciclo de produção (com base na matéria natural)

\begin{tabular}{|c|c|c|c|c|c|}
\hline \multirow{2}{*}{ Ingrediente } & \multicolumn{5}{|c|}{ Cálcio (\%) } \\
\hline & 2,2 & 2,6 & 3,0 & 3,4 & 3,8 \\
\hline Milho & 47,900 & 47,900 & 47,900 & 47,900 & 47,900 \\
\hline Farelo de soja (45\%) & 35,400 & 35,400 & 35,400 & 35,400 & 35,400 \\
\hline Óleo de soja & 5,482 & 5,482 & 5,482 & 5,482 & 5,482 \\
\hline Calcário & 4,753 & 5,795 & 6,837 & 7,878 & 8,920 \\
\hline Fosfato bicálcico & 1,124 & 1,124 & 1,124 & 1,124 & 1,124 \\
\hline Sal comum & 0,354 & 0,354 & 0,354 & 0,354 & 0,354 \\
\hline DL-Metionina $(99 \%)$ & 0,349 & 0,349 & 0,349 & 0,349 & 0,349 \\
\hline L-Lisina $\mathrm{HCl}(79 \%)$ & 0,145 & 0,145 & 0,145 & 0,145 & 0,145 \\
\hline L-Treonina $(98 \%)$ & 0,047 & 0,047 & 0,047 & 0,047 & 0,047 \\
\hline Cloreto de colina $(60 \%)$ & 0,100 & 0,100 & 0,100 & 0,100 & 0,100 \\
\hline Mistura vitamínica $^{1}$ & 0,100 & 0,100 & 0,100 & 0,100 & 0,100 \\
\hline Mistura mineral $^{2}$ & 0,050 & 0,050 & 0,050 & 0,050 & 0,050 \\
\hline Antioxidante $^{3}$ & 0,010 & 0,010 & 0,010 & 0,010 & 0,010 \\
\hline Antibiótico ${ }^{4}$ & 0,010 & 0,010 & 0,010 & 0,010 & 0,010 \\
\hline Inerte $^{5}$ & 4,176 & 3,134 & 2,092 & 1,051 & 0,009 \\
\hline Total & 100,000 & 100,000 & 100,000 & 100,000 & 100,000 \\
\hline \multicolumn{6}{|l|}{ Composição nutricional calculada } \\
\hline Energia metabolizável (Kcal/kg) & 2.900 & 2.900 & 2.900 & 2.900 & 2.900 \\
\hline Proteína bruta $(\%)$ & 20,00 & 20,00 & 20,00 & 20,00 & 20,00 \\
\hline Lisina total $(\%)$ & 1,210 & 1,210 & 1,210 & 1,210 & 1,210 \\
\hline Lisina digestível (\%) & 1,118 & 1,118 & 1,118 & 1,118 & 1,118 \\
\hline Metionina + cistina total $(\%)$ & 0,968 & 0,968 & 0,968 & 0,968 & 0,968 \\
\hline Metionina + cistina dig. (\%) & 0,894 & 0,894 & 0,894 & 0,894 & 0,894 \\
\hline Treonina total $(\%)$ & 0,783 & 0,783 & 0,783 & 0,783 & 0,783 \\
\hline Treonina digestível (\%) & 0,730 & 0,730 & 0,730 & 0,730 & 0,730 \\
\hline Triptofano total $(\%)$ & 0,253 & 0,253 & 0,253 & 0,253 & 0,253 \\
\hline Triptofano digestível (\%) & 0,227 & 0,227 & 0,227 & 0,227 & 0,227 \\
\hline Fibra bruta $(\%)$ & 2,744 & 2,744 & 2,744 & 2,744 & 2,744 \\
\hline Cálcio (\%) & 2,2 & 2,6 & 3,0 & 3,4 & 3,8 \\
\hline Fósforo total (\%) & 0,51 & 0,51 & 0,51 & 0,51 & 0,51 \\
\hline Fósforo disponível (\%) & 0,31 & 0,31 & 0,31 & 0,31 & 0,31 \\
\hline Sódio $(\%)$ & 0,157 & 0,157 & 0,157 & 0,157 & 0,157 \\
\hline
\end{tabular}

${ }^{1}$ Composição/kg do produto: vit.A: 12.000.000U.I.; vit.D ${ }_{3}$ : 3.600.000U.I.; vit.E: 3.500U.I.; vit.B ${ }_{1}$ : 2.500mg; vit.B ${ }_{2}$ : $8.000 \mathrm{mg}$; vit. $\mathrm{B}_{6}: 5.000 \mathrm{mg}$; ácido pantotênico: $12.000 \mathrm{mg}$, Biotina: $200 \mathrm{mg}$, vit.K: $3.000 \mathrm{mg}$; ácido fólico: $1.500 \mathrm{mg}$; ácido nicotínico: $40.000 \mathrm{mg}$; vit. $\mathrm{B}_{12}: 20.000 \mathrm{mg}$; selênio: $150 \mathrm{mg}$; veículo q.s.p.: $1.000 \mathrm{~g}$;

${ }^{2}$ Composição/kg do produto: Mn: 160g; Fe: $100 \mathrm{~g}$; Zn: $100 \mathrm{~g}$; Cu: $20 \mathrm{~g}$; Co: 2g; I: $2 \mathrm{~g}$; veículo q.s.p.: $1000 \mathrm{~g}$; ${ }^{3}$ butilhidróxi-tolueno (99\%); ${ }^{4}$ avilamicina $10 \% ;{ }^{5}$ areia lavada.

Os parâmetros de desempenho foram avaliados pela produção média de ovos por ave/dia $(\%)$ e por ave/alojada (\%), peso dos ovos (g), massa de ovos (g), consumo de ração (g de ração/ave-dia), conversão alimentar (g de ração por dúzia e por massa de ovos) e viabilidade (\%).

No caso dos parâmetros de qualidade interna e externa dos ovos, avaliaram-se: produção de ovos viáveis para comercialização $(\mathrm{POVC})=\left(\mathrm{n}^{\circ}\right.$ total de ovos viáveis produzidos por unidade experimental número total de ovos produzidos) $\mathrm{x}$ 100); produção de ovos viáveis por ave-dia $($ POVD $)=($ taxa de postura $(\%) \times$ total de ovos viáveis)/(número total de ovos produzidos), peso específico $\left(\mathrm{g} / \mathrm{cm}^{3}\right)$, peso da casca $(\mathrm{mg})$, porcentagem da casca $(\%)$, peso de albúmen $(\mathrm{g})$, porcentagem do albúmen $(\%)$, peso da gema $(\mathrm{g})$, porcentagem da gema (\%), espessura da casca $(\mathrm{mm})$, altura e diâmetro dos ovos $(\mathrm{mm})$ e teores de $\mathrm{Ca}, \mathrm{P}, \mathrm{Mg}$ e cinza (\%) na casca dos ovos. 
O peso específico dos ovos foi determinado pelo método de flutuação salina, conforme metodologia descrita por Hamilton (1982). No $16^{\circ}, 17^{\circ}$ e $18^{\circ}$ dias de cada um dos quatro períodos experimentais de 21 dias, todos os ovos íntegros coletados foram imersos em soluções de $\mathrm{NaCl}$ com densidade variando de 1,055 a $1,100 / \mathrm{cm}^{3}$, com intervalos de $0,005 \mathrm{~g} / \mathrm{cm}^{3}$ entre elas, totalizando 10 soluções, sendo o peso específico medido por meio de um densímetro.

Quatro ovos de cada unidade experimental (UE), coletados aleatoriamente no $19^{\circ}, 20^{\circ}$ e $21^{\circ}$ dia de cada período, foram pesados individualmente em balança com precisão de 0,001g. Após a pesagem, foram identificados e quebrados. A gema de cada ovo foi pesada, e a respectiva casca foi lavada e seca ao ar, para obtenção de seu peso, calculado pela diferença entre os pesos total e do albúmen.

Foi realizada a análise de variância a $5 \%$ de probabilidade, utilizando-se o Programa SAEG (Sistema..., 2004). Posteriormente, os efeitos dos níveis de cálcio foram estimados por meio de análise das variáveis pelo modelo de regressão linear e quadrática, levando-se em consideração o comportamento biológico das aves.

\section{RESULTADOS E DISCUSSÃO}

A temperatura máxima obtida foi de $23,7 \pm 2,3^{\circ} \mathrm{C}$, e a mínima de $18,5 \pm 3,1^{\circ} \mathrm{C}$. A umidade relativa foi de $82,4 \pm 1,8 \%$. O efeito do nível de Ca sobre as variáveis de desempenho é apresentado na Tab. 2.

Tabela 2. Desempenho de codornas japonesas alimentadas com dietas com diferentes porcentagens de cálcio

\begin{tabular}{|c|c|c|c|c|c|c|c|}
\hline \multirow{2}{*}{ Variável } & \multicolumn{5}{|c|}{$\mathrm{Ca}(\%)$} & \multirow{2}{*}{$\begin{array}{l}\text { Valor } \\
\text { de P }\end{array}$} & \multirow{2}{*}{ CV\% } \\
\hline & 2,2 & 2,6 & 3,0 & 3,4 & 3,8 & & \\
\hline Consumo de ração (g) & 26,42 & 26,26 & 26,03 & 25,81 & 25,84 & ns & 5,51 \\
\hline Prod. ovos-ave/dia (\%) & 76,82 & 77,90 & 75,05 & 77,60 & 80,20 & ns & 6,24 \\
\hline Prod. ovos-ave/alojada (\%) & 71,12 & 73,61 & 70,17 & 72,99 & 76,36 & ns & 7,23 \\
\hline Peso médio do ovo $(\mathrm{g})$ & 11,78 & 11,96 & 11,85 & 12,02 & 11,93 & ns & 2,70 \\
\hline Massa de ovo (g/ave/dia) & 9,06 & 9,31 & 8,89 & 9,32 & 9,57 & ns & 6,92 \\
\hline Conversão MO (g/g) & 2,93 & 2,82 & 2,93 & 2,78 & 2,71 & $\mathrm{P}<0,05^{*}$ & 5,89 \\
\hline Conversão DZ (kg/g) & 0,41 & 0,40 & 0,42 & 0,40 & 0,39 & $\mathrm{P}<0,05^{*}$ & 5,70 \\
\hline Viabilidade $(\%)$ & 85,71 & 85,71 & 82,86 & 88,57 & 88,57 & ns & 12,08 \\
\hline
\end{tabular}

MO- massa de ovo; DZ- dúzia de ovo.

* Efeito linear.

ns: não significativo $(\mathrm{P}>0,05)$. CV: coeficiente de variação.

$\mathrm{O}$ teor de $\mathrm{Ca}$ não influenciou $(\mathrm{P}>0,05)$ o consumo de ração. $\mathrm{O}$ mesmo fato foi constatado por Costa et al. (2007) e Pizzolante et al. (2007), ao trabalharem com codornas japonesas.

Assim como ocorreu com o consumo de ração, os teores de Ca testados nas dietas também não influenciaram $(\mathrm{P}>0,05)$ a produção média de ovos por ave/dia. O valor médio da produção do lote, ou seja, da produção de todas as aves envolvidas no experimento, foi de $77,5 \%$. Pizzolante et al. (2007), ao trabalharem com codornas japonesas com 54 semanas de idade, com o intuito de testarem o efeito do horário de fornecimento das rações com diferentes níveis de Ca $(1,25 ; 2,50$ e $3,75 \%)$ sobre o desempenho e a qualidade dos ovos, também não encontraram diferença estatística para a taxa de postura das aves. Esses autores observaram produção média do lote equivalente a $76,8 \%$.

A produção média de ovos por ave/alojada não sofreu influência $(\mathrm{P}>0,05)$ da porcentagem de $\mathrm{Ca}$ da dieta, uma vez que a produção média de ovos por ave/dia não variou significativamente $(\mathrm{P}>0,05)$. A viabilidade também não foi influenciada $(\mathrm{P}>0,05)$ pela porcentagem de $\mathrm{Ca}$ na dieta.

Por se tratar de aves que já se encontravam no terço final do ciclo de produção, torna-se importante ressaltar que o equivalente à mortalidade média do lote não ultrapassou $12 \%$ e que $4,8 \%$ das mortes se deram por prolapso. Estes resultados são condizentes com os encontrados por Costa et al. (2007), que também não verificaram efeito $(\mathrm{P}>0,05)$ da porcentagem 
de $\mathrm{Ca}$ sobre as duas variáveis mencionadas anteriormente.

O peso médio e a massa de ovos também não foram influenciados $(\mathrm{P}>0,05)$ pela porcentagem de Ca estudada.

Verificou-se que as aves que consumiram dietas que continham a maior porcentagem de $\mathrm{Ca}$ testada $(3,8 \%)$ apresentaram melhor conversão alimentar por massa de ovos, quando comparadas àquelas que receberam menos $\mathrm{Ca}$ $(2,2 \%)$ durante todo o período experimental. O efeito foi linear decrescente $(\mathrm{P}<0,05)$, indicando que, quando se aumentam os níveis de $\mathrm{Ca}$ na dieta, a conversão por massa de ovos tende a melhorar.

Também foi observado efeito linear decrescente $(\mathrm{P}<0,05)$, ao se estudar a conversão alimentar por dúzia de ovos, indicando que a melhor porcentagem testada $(3,8 \%$ de $\mathrm{Ca})$ foi a que apresentou melhor conversão alimentar.

As variáveis relacionadas à qualidade dos ovos segundo a porcentagem de Ca são apresentadas na Tab. 3.

As equações de regressão estimadas para os valores de desempenho e a qualidade dos ovos encontram-se na Tab. 4.

Tabela 3. Qualidade dos ovos de codornas japonesas alimentadas com dietas com diferentes porcentagens de cálcio

\begin{tabular}{|c|c|c|c|c|c|c|c|}
\hline \multirow{2}{*}{ Variável } & \multicolumn{5}{|c|}{$\mathrm{Ca}(\%)$} & \multirow{2}{*}{$\begin{array}{l}\text { Valor } \\
\text { de P }\end{array}$} & \multirow{2}{*}{$\mathrm{CV} \%$} \\
\hline & 2,2 & 2,6 & 3,0 & 3,4 & 3,8 & & \\
\hline Ovo viav. comerc. $(\%)^{\#}$ & 95,45 & 96,66 & 96,21 & 96,92 & 97,47 & ns & 2,19 \\
\hline Ovo viav/ave/dia (\%) & 73,34 & 75,24 & 72,24 & 75,30 & 78,14 & ns & 6,82 \\
\hline Peso específico $\left(\mathrm{g} / \mathrm{cm}^{3}\right)$ & 1,067 & 1,069 & 1,071 & 1,068 & 1,070 & ns & 0,33 \\
\hline Peso de casca $(\mathrm{g})$ & 0,904 & 0,850 & 0,861 & 0,901 & 0,916 & $\mathrm{P}<0,05^{* *}$ & 4,99 \\
\hline Casca $(\%)$ & 7,12 & 6,81 & 7,05 & 7,42 & 7,50 & $\mathrm{P}<0,05^{*}$ & 5,85 \\
\hline Peso de albúmen $(\mathrm{g})$ & 7,86 & 7,75 & 7,77 & 7,50 & 7,57 & ns & 4,69 \\
\hline Albúmen (\%) & 61,73 & 62,17 & 63,14 & 61,77 & 62,04 & $\mathrm{~ns}$ & 2,42 \\
\hline Peso de gema (g) & 3,97 & 3,87 & 3,65 & 3,75 & 3,72 & $\mathrm{P}<0,01^{*}$ & 4,25 \\
\hline Gema $(\%)$ & 31,16 & 31,02 & 29,94 & 30,82 & 30,46 & ns & 4,22 \\
\hline Ca na casca $(\%)$ & 37,19 & 36,73 & 36,11 & 35,11 & 35,80 & $\mathrm{P}<0,01 *$ & 3,22 \\
\hline P na casca $(\%)$ & 0,316 & 0,315 & 0,284 & 0,287 & 0,284 & $\mathrm{P}<0,01 *$ & 8,18 \\
\hline Mg na casca $(\%)$ & 0,658 & 0,636 & 0,626 & 0,604 & 0,610 & $\mathrm{P}<0,01 *$ & 4,91 \\
\hline Cinzas na Casca $(\%)$ & 74,20 & 74,66 & 74,09 & 74,11 & 73,13 & ns & 5,79 \\
\hline Espessura casca (mm) & 0,188 & 0,195 & 0,190 & 0,191 & 0,198 & $\mathrm{P}<0,01 *$ & 2,59 \\
\hline Altura do ovo (mm) & 33,11 & 33,01 & 32,73 & 33,34 & 32,51 & ns & 2,20 \\
\hline Diâmetro do ovo (mm) & 25,85 & 25,62 & 25,63 & 25,89 & 25,44 & ns & 2,16 \\
\hline
\end{tabular}

"Produção de ovos viáveis para comercialização e produção de ovos viáveis-ave/dia.

*Efeito linear.

**Efeito quadrático.

ns: não significativo, $\mathrm{P}>0,05 ; \mathrm{CV}$ : coeficiente de variação.

Tabela 4. Equações de regressão estimadas para os valores de desempenho (Y) e a qualidade dos ovos (Y), em função do nível de suplementação de cálcio $(\mathrm{X})$ à dieta

\begin{tabular}{llc}
\multicolumn{1}{c}{ Variável } & \multicolumn{1}{c}{ Equação } & $\mathrm{R}^{2}$ \\
\hline Conversão MO $(\mathrm{g})$ & $\hat{\mathrm{Y}}=3,20096-0,122782 \mathrm{X}$ & 0,64 \\
Conversão DZ $(\mathrm{Kg})$ & $\hat{\mathrm{Y}}=0,448079-0,0145197 \mathrm{X}$ & 0,61 \\
Peso de casca $(\mathrm{mg})$ & $\hat{\mathrm{Y}}=1,47828-0,429640 \mathrm{X}+0,0747927 \mathrm{X}^{2}$ & 0,76 \\
Casca $(\%)$ & $\hat{\mathrm{Y}}=6,14890-0,343555 \mathrm{X}$ & 0,59 \\
Peso de gema $(\mathrm{g})$ & $\hat{\mathrm{Y}}=4,26664-0,157155 \mathrm{X}$ & 0,60 \\
Ca na casca $(\%)$ & $\hat{\mathrm{Y}}=39,4880-1,09989 \mathrm{X}$ & 0,74 \\
P na casca $(\%)$ & $\hat{\mathrm{Y}}=0,366691-0,0230321 \mathrm{X}$ & 0,75 \\
Mg na casca $(\%)$ & $\hat{\mathrm{Y}}=0,723236-0,0321071 \mathrm{X}$ & 0,87 \\
Espessura de casca $(\mathrm{mm})$ & $\hat{\mathrm{Y}}=0,179391+0,00436095 \mathrm{X}$ & 0,44 \\
\hline
\end{tabular}

MO: massa de ovos; DZ: dúzia de ovos. 
$\mathrm{O}$ aumento da porcentagem de $\mathrm{Ca}$ na dieta não aumentou $(\mathrm{P}>0,05)$ a produção de ovos viáveis para a comercialização e também não foi capaz de alterar $(\mathrm{P}>0,05)$ o peso específico dos ovos, o peso $\mathrm{e}$ a porcentagem de albúmen, a porcentagem de gema e a altura e o diâmetro médio dos ovos (Tab. 4). No entanto, a porcentagem de $\mathrm{Ca}$ na dieta influenciou $(\mathrm{P}<0,05)$ o peso e a porcentagem da casca, o peso da gema e a espessura da casca. Estes resultados estão parcialmente de acordo com os de Costa et al. (2007), que observaram efeito significativo da porcentagem de $\mathrm{Ca}$ sobre o peso e a porcentagem de casca, o peso específico do ovo, a espessura de casca e a porcentagem de Ca na casca.

Houve efeito quadrático $(\mathrm{P}<0,05)$ para o peso da casca, indicando que a porcentagem de $\mathrm{Ca}$ na dieta, que minimiza essa variável nos ovos analisados, foi equivalente a $2,9 \%$. O aumento do $\mathrm{Ca}$ na dieta aumentou $(\mathrm{P}<0,01)$, de forma linear, a porcentagem de casca, e não influenciou significativamente o peso e a porcentagem de albúmen dos ovos (Tab. 4). Estes resultados estão de acordo com os encontrados por Costa et al. (2007).

A espessura de casca foi influenciada $(\mathrm{P}<0,01)$ pelo aumento do $\mathrm{Ca}$ na dieta - efeito linear crescente -, indicando como recomendável incluir, no mínimo, 3,8\% de $\mathrm{Ca}$ na dieta de codornas japonesas após o pico de postura, para obtenção de maior espessura de casca e, consequentemente, menores perdas, devido a eventuais quebras e trincas nos ovos. No entanto, verificou-se redução linear nos teores de $\mathrm{Ca}, \mathrm{P}$ e $\mathrm{Mg}$ na casca dos ovos com o aumento do $\mathrm{Ca}$ na dieta. Pode-se inferir que as porcentagens mais baixas de $\mathrm{Ca}$ favoreceram a maior deposição desses minerais na casca, o que certamente não garante melhor e maior resistência à quebra dos ovos, uma vez que o efeito observado para a espessura da casca foi exatamente contrário à deposição dos minerais na casca.

Resultado semelhante foi observado por Costa et al. (2007), que estudaram duas porcentagens (2,5 e $3,2 \%)$ de $\mathrm{Ca}$ em dietas para codornas japonesas, durante o pico de postura, e constataram aumento significativo na espessura da casca dos ovos produzidos e redução linear na concentração de Ca na casca.
Fisiologicamente, esse resultado pode ser explicado pelo fato de que, quando o $\mathrm{Ca}$ é fornecido em porcentagens baixas na dieta, há maior produção da proteína ligadora de cálcio, aumentando a eficiência de absorção e melhorando o aproveitamento do $\mathrm{Ca}$. No entanto, essa melhora ocorre até determinada porcentagem, a partir da qual a elevação dos teores de $\mathrm{Ca}$ reduz a absorção, comprovando que, sob baixa disponibilidade, há maior eficiência de utilização desse mineral (Dell'Isola e Baião, 2001).

$\mathrm{Na}$ verdade, o aumento da inclusão de $\mathrm{Ca}$ na ração, com o objetivo de melhorar a casca dos ovos, é uma prática que visa melhorar a qualidade da casca dos ovos produzidos por aves do segundo ciclo de produção (poedeiras comerciais) e de terço final do ciclo de produção (codornas de postura). Além disso, como a espessura da casca aumenta com o aumento da inclusão de $\mathrm{Ca}$ na dieta, pode-se inferir que porcentagens crescentes desse mineral poderiam produzir, indiretamente (potencialização do $\mathrm{P}$ na formação da matriz da casca), membranas da casca mais resistentes e não cascas mais calcificadas. Isso explicaria a redução na deposição de $\mathrm{Ca}$ na casca a partir do aumento da porcentagem desse mineral na ração.

De acordo com os resultados obtidos, houve efeito linear decrescente $(\mathrm{P}<0,01)$ para o peso da gema dos ovos. Verifica-se que à medida que se aumenta o $\mathrm{Ca}$ da dieta, ocorre significativa redução no peso da gema, indicando $2,2 \%$ de $\mathrm{Ca}$ como sendo a porcentagem recomendável, diante das condições estudadas. No entanto, o mesmo fato não foi observado para a porcentagem de gema $(\mathrm{P}>0,05)$ (Tab. 3).

Ao se estudar a altura e o diâmetro médio dos ovos, observou-se não haver efeito $(\mathrm{P}>0,05)$ da porcentagem de $\mathrm{Ca}$ testada sobre estas variáveis. Estes resultados estão de acordo com os encontrados por Costa et al. (2007), que também não observaram $(\mathrm{P}>0,05)$ efeito da porcentagem de Ca sobre a altura e o diâmetro do ovos.

Desse modo, 2,2\% de Ca proporcionaram bom desempenho e boa qualidade dos ovos em quase todas as variáveis analisadas, exceto para conversão alimentar por massa e por dúzia de ovos, e peso, porcentagem e espessura da casca, todos tendo como satisfatórios $3,8 \%$ de $\mathrm{Ca}$, com 
exceção do peso da casca, que teve como satisfatória a inclusão de $2,9 \%$ de Ca. Diferentemente, Brandão et al. (2007), ao trabalharem com codornas japonesas de 46 a 130 dias de vida, recomendaram $3,5 \%$ de $\mathrm{Ca}$ na dieta para otimizar os índices de desempenho sem afetar negativamente a qualidade interna $\mathrm{e}$ externa dos ovos.

\section{CONCLUSÕES}

Dieta que contenha $3,8 \%$ de $\mathrm{Ca}$, correspondendo ao consumo diário de $982 \mathrm{mg}$ por ave, melhora a conversão alimentar e a qualidade da casca dos ovos de codornas japonesas no terço final do ciclo de produção (45 a 57 semanas de idade).

\section{REFERÊNCIAS BIBLIOGRÁFICAS}

BRANDÃO, P.A.; COSTA, F.G.P.; SILVA, J.H.V. et al. Exigência de cálcio para codornas japonesas (coturnix coturnix japonica) em postura. Acta Sci., v.29, p.17-21, 2007.

COSTA, C.H.R.; BARRETO, S.L.; MOURA, W.C.O. et al. Níveis de fósforo e cálcio em dietas para codornas japonesas em postura. Rev. Bras. Zootec., v.36, supl., p.2037-2046, 2007.

DELL'ISOLA, A.T.P.; BAIÃO, N.C. Cálcio e fósforo para galinhas poedeiras - Avicultura. Cad. Tec. Vet. Zootec., n.34, p.65-92, 2001.

HAMILTON, R.M.G. Methods and factors that affect the measurement of egg shell quality. Poult. Sci., v.61, p.2022-2039, 1982.

INSTITUT NATIONAL DE LA RECHERCHE AGRONOMIQUE. Alimentação dos animais monogástricos: suínos, coelhos e aves. 2.ed. São Paulo: Roca, 1999. 245p.
MURAKAMI, A.E.; ARIKI, J. Produção de codornas japonesas. Jaboticabal: Funep-Unesp, 1998. 79p.

NUTRIENT requirements of poultry. 9.ed. Washington: National Academy of Sciences, 1994. 155p.

PINTO, R.; FERREIRA, A.S.; DONZELE, J.L. et al. Exigência de metionina mais cistina para codornas japonesas em postura. Rev. Bras. Zootec., v.32, p.1166-1173, 2003a.

PINTO, R.; FERREIRA, A.S.; DONZELE, J.L. et al. Exigência de lisina para codornas japonesas em postura. Rev. Bras. Zootec., v.32, p.11821189, 2003b.

PINHEIRO, S.R.; BARRETO, S.L.T.; ALBINO, L.F.T. et al. Efeito dos níveis de triptofano digestível em dietas para codornas japonesas em postura. Rev. Bras. Zootec., v.37, p.1012-1016, 2008.

PIZZOLANTE, C.C.; SALDANHA, E.S.P.B.; GARCIA, E.A. et al. Efeito do horário de fornecimento de rações contendo diferentes níveis de cálcio sobre o desempenho produtivo e qualidade de ovos de codornas japonesas (Coturnix japonica) em final de produção. Rev. Cienc. Anim. Brasil., v.8, p.677-683, 2007.

RECOMENDAÇÃO para a nutrição animal. 5.ed. France: Rhône Poulenc, 1987. 86p.

SHIRIVASTAV, A.K.; PANDA, B. A review of quail nutrition research in India. World's $J$. Poult. Sci., v.55, p.73-81, 1999.

SISTEMA para análises estatísticas - SAEG. Viçosa: UFV, 2004. 59p.

UMIGI, R.T.; BARRETO, S.L.; DONZELE, J.L. et al. Níveis de treonina digestível em dietas para codorna japonesa em postura. Rev. Bras. Zootec., v.36, p.1868-1874, 2007. 